\title{
PROSPECTIVE AND RETROSPECTIVE MEMORY IN MILD ALZHEIMER'S DISEASE
}

\author{
Sergilaine Pereira Martins', Benito Pereira Damasceno²
}

\begin{abstract}
Objective: To study prospective and retrospective memory in patients with mild Alzheimer's disease (AD). Method: Twenty mild AD and 20 matched normal control subjects were included. Diagnosis of AD was based on DSM-IV and NINCDS-ADRDA criteria, using CDR 1 and MMSE scores from 16 to 24 for mild AD. All subjects underwent retrospective (Rey Auditory Verbal Learning Test, RAVLT) and prospective memory tests (the appointment and belonging subtests of the Rivermead Behavioral Memory Test, RBMT; and two tests made to this study: the clock and the animals test), as well as MMSE, neuropsychological counterproofs, and Cornell Scale for Depression in Dementia. The data was analyzed with Wilcoxon test and Spearman correlation coefficient. Results: AD patients performed worse than controls in prospective and retrospective memory tests, with poorer performance in retrospective memory. There was no correlation between prospective memory and attention, visual perception, executive function, or depression scores. Conclusion: Prospective and, in higher degree, retrospective memory are primarily and independently impaired in mild AD.
\end{abstract}

KEY-WORDS: prospective memory, Alzheimer's disease, dementia, neuropsychological tests.

\begin{abstract}
Memória prospectiva e retrospectiva na doença de Alzheimer leve
Resumo - Objetivo: Estudar a memória prospectiva e retrospectiva em pacientes com doença de Alzheimer (DA) leve. Método: Vinte pacientes com DA leve e 20 sujeitos controles normais pareados foram incluídos. $O$ diagnóstico de DA baseou-se nos critérios DSM-IV e NINCDS-ADRDA, usando CDR 1 e escores do Mini-Exame Mental de 16 a 24 para DA leve. Todos os sujeitos foram submetidos a testes de memória retrospectiva (Teste de Rey para Aprendizado Auditivo-Verbal) e prospectiva (os testes da consulta e do pertence da Bateria Comportamental de Memória do Rivermead; e dois testes desenvolvidos para este estudo: o teste do relógio e o dos animais), bem como a testes cognitivos controles e Escala Cornell de Depressão em Demência. A análise dos dados usou o teste de Wilcoxon e o coeficiente de correlação de Spearman. Resultados: Os pacientes com DA foram inferiores aos controles nos testes de memória prospectiva e retrospectiva, em maior grau nesta última, sem que seu desempenho tenha se correlacionado com déficit de atenção, percepção ou função executiva. Conclusão: A memória prospectiva e, em maior grau, a memória retrospectiva estão primariamente e independentemente alteradas na DA leve.
\end{abstract}

PALAVRAS-CHAVE: memória prospectiva, doença de Alzheimer, demência, testes neuropsicológicos.

Memory complaints are usually the first and most important symptoms among Alzheimer's disease (AD) patients. Impaired ability to learn new information or to recall previously learned information (i.e., retrospective episodic memory) is required for the operational diagnosis of the disease'. Memory is, however, a complex functional system and other types of memory (e.g., semantic, prospective) may be impaired early in AD. Episodic, semantic, and working memory are the most studied in AD. As conceived of by Tulving ${ }^{2}$, episodic retrospective memory (RetM) represents events in our personal biographic his- tory. It involves conscious recollection of these episodes (for example, when one was getting married), and it is typically evaluated by means of learning a list of words or a series of figures. Semantic memory constitutes our conceptual knowledge, for example, knowing that one is married without taking into account the time and place (episode) of the marriage; and working memory (as proposed by Baddeley) ${ }^{3}$ refers to the temporary, short-term storage of verbal-phonological, spatial and sensory informations that are being processed in any of a range of cognitive tasks (for example, when interpreting, learning, or reason-

Medical School, State University of Campinas, SP, Brazil: 'Postgraduate Neurologist, ${ }^{2}$ Professor, Department of Neurology.

Received 11 December 2007, received in final form 10 March 2008. Accepted 29 March 2008.

Dr. Benito P. Damasceno - Department of Neurology, Medical School / State University of Campinas (UNICAMP) - Box 6111 - $13083-970$ - Campinas SP - Brasil. E-mail: damascen@unicamp.br 
ing). In AD, RetM deficit, particularly the free and delayed recall of series of words, sentences, or objects, occurs earlier than the medial temporal atrophy shown by magnetic resonance imaging, and it is considered the most reliable predictor of the disease in its preclinical stage ${ }^{4}$. Impairment of prospective memory (ProM), though a common complaint of $A D$ patients, has been neglected in cognitive studies of the disease. While RetM is the memory of the past, ProM is the memory of the future. ProM consists in remembering to carry out intended actions at an appropriate point in the future, such as to give your housemate the message that a friend called, keep appointments, pay bills, take medicine, and carry out domestic chores, so it is crucial for an older person to function independently in an everyday life context ${ }^{5}$. To perform a ProM task, one must remember there was an intention (the prospective component) and also to remember the contents of the intention, "what to do" (the retrospective component). ProM tasks can be either time-based (to make an intended action at a particular time of day or after a certain period of time has elapsed), event-based (to execute the intended action upon the occurrence of a particular environmental event), or activity-based (to do something when a particular activity has been completed $)^{5,7}$.

Several studies ${ }^{8-10}$ have shown that ProM is the memory type that most declines with aging, particularly when the prospective action is cued only by the time at which it has to be performed. Differential effects of aging on memory are more remarkable when the elderly has to rely on internal, self-initiated reminding, and less when there are more environmental, external cues, so that age differences are large in prospective tasks ("remembering to remember") and in free recall, and less in cued recall, and less again in recognition memory ${ }^{8}$. Other studies have provided evidence that ProM is sensitive to both aging and early onset $A D$, and that ProM impairment could be an indicator of the disease in its very earliest detectable forms, particularly when associated with apolipoprotein E \&4 allele ${ }^{11-13}$.

The main purpose of our study is to compare the performance of prospective and retrospective memory in patients with mild $A D$ and matched normal controls. Since ProM seems to be the most vulnerable to the aging process, we hypothesize it would be more impaired than RetM in these $A D$ patients.

\section{METHOD}

We studied 40 subjects, comprising 20 with mild AD attended at the Unit for Neuropsychology and Neurolinguistics (UNICAMP Clinic Hospital), and 20 normal controls. Routine laboratory examinations for dementia assessment (including B12 and folate dosage, sorology for syphilis, thyroid hormones) and brain computed tomography were carried out in all patients.
This study was approved by our Medical School Ethics Committee and all subjects signed the informed consent form.

The diagnosis of probable mild AD was based on DSM-IV and NINCDS-ADRDA criteria ${ }^{14}$. We included only patients with scores between 16 and 24 on Mini-Mental State Examination (MMSE) $)^{15,16}$ and score 1 on Clinical Dementia Rating (CDR) ${ }^{17}$. Exclusion criteria were history of other neurological or psychiatric diseases, head injury with loss of consciousness, use of sedative drugs until 24 hours before the neuropsychological assessment, drug or alcohol addiction and prior exposition to neurotoxic substances. The control group consisted of subjects matched to the patients for age ( \pm 5 years) and education ( \pm 2 years), with CDR 0 , and without previous history of neurological or psychiatric disease, or memory complaints. All patients were submitted to a detailed interview (even with the caregiver), the MMSE, and neuropsychological tests.

Neuropsychological evaluation comprised following tests

1) Retrospective episodic memory was examined with Rey auditory verbal learning test (RAVLT) ${ }^{18}$, which consists of fifteen words read aloud for five consecutive trials (list A), followed by a free-recall test. After the fifth trial, a new interference list of fifteen words is presented (list B) followed by a free-recall of that list. Soon afterwards, a free-recall of the first list is tested without new presentation. After a twenty-minute delay period, subjects are again required to recall words from list A. Finally, the patient must identify list $A$ words from a list of fifty words which includes lists $A$ and $B$ and twenty other words phonemically or semantically related to lists $A$ and $B$.

2) Prospective memory was evaluated with two subtests of the Rivermead Behavioral Memory Test (RBMT: the appointment and the belonging test; after Wilson, Cockburn and Baddeley $)^{19}$; and two tests developed by the authors: the animals and the clock test. The ProM total score varied from 0 to 10.

2.1) Remembering an appointment: the subjects are required to ask for their next appointment when they hear the ringing of the alarm clock, which is set to go off 15 minutes after the instruction is given. Scoring system: 1 point if the correct response was made following a prompt ("What were you going to do when the alarm rang?") and 2 points if it was made without a prompt (maximum score $=2$ ).

2.2) Remembering a belonging: at the beginning of the session, the examiner borrows from the subject a personal belonging (pen, comb), which the examiner hides at sight of the subject (e.g., into a drawer or cupboard) with an instruction that the subject ask for it to be returned at the end of the test session. Then, at the end of the session, the examiner says "That is the end of the testing session". If the subject does not spontaneously request the belonging the examiner gives a prompt: "Was there something you were going to ask me for?" Scoring: 1 point if the subject recalled the item, another if he recalled the location and additional points for each response which was made without a prompt (maximum score=4). 
2.3) Animals' test: subjects are told that they are going to see 20 photographs of animals on the computer screen, one at a time (during five seconds), and that his (her) task is to name each animal (naming task) and, in case he (she) sees some object or food in the mouth of the animal, to inform this to the examiner (this is the ProM task, embedded in the naming task). For the ProM task there are two photographs: one in the fifth and another in the tenth position. Scoring: 1 point for each correct ProM response (maximum=2 points).

2.4) Clock test: at the beginning of the session, the subject is asked to remind the examiner of an appointment five minutes afterwards, with the instruction: "In five minutes I have to tell to the nurse about a medication. Could you please remind me to tell to her when five minutes has passed?" This time is occupied with other tests or activities. There must be a clock visible in the periphery of the subject visual field. Scoring: 2 points if the subject reminds the examiner after five minutes with an error of $( \pm$ ) 30 seconds; 1 point for errors higher than this (and 0 point if no reminding); (maximum score $=2$ ).

3) Control tests (counterproofs) comprised: (a) visual perception (10 abstract figures modified from Jones-Gotman et al. (2); $^{20}$; (b) attention: the forward and backward digit span subtest of WAIS- $\mathrm{R}^{21}$; (c) executive function: Trail Making A and $\mathrm{B}^{22}$; and (d) Cornell Scale for Depression in Dementia (CSDD; Brazilian version adapted by Carthery-Goulart et al. $)^{23}$.

All subjects were asked to repeat the ProM instructions to ensure they had understood them. Before the execution of digit span, trail making, and animals' ProM tasks, the subjects underwent a short learning (training) trial.

Data analysis by means of Statistica software 6.0 used Student $t$ test for intergroup (paired samples) comparisons of demographic data (age and educational level), Wilcoxon test to compare RetM and ProM scores, and Spearman coefficient for correlation between PM and counterproofs. Statistical significance considered was $\mathrm{p}<0.05$.

\section{RESULTS}

Demographic and neuropsychological data are presented in the Table. There were 9 men and 11 women in each group. Dementia patients had higher age (mean $75.6 \pm$ standard deviation 7.8 versus $74.1 \pm 6.8$ years; $t=2.6252$, $\mathrm{p}=0.02$ ) but similar educational level as controls (5.6 \pm 4.5 versus $5.8 \pm 4.4$ years; $p=0.507$ ). They performed as well as controls on Digit Span forward $(p=0.324)$ and Trail Making A $(p=1.00)$, but worse on MMSE (22.6 \pm 1.9 versus 29.0 $\pm 1.3 ; p=0.0001)$, Digit Span backwards (3.3 \pm 0.7 versus 4.0 $\pm 0.9 ; p=0.0005)$, Trail Making $B(12.3 \pm 5.7$ versus 21.0 $\pm 6.0 ; p=0.0001)$, Visual Perception $(8.1 \pm 1.3$ versus 9.0 $\pm 0.9 ; p=0.015)$, RAVLT delayed recall (1.1 \pm 1.6 versus 6.65 $\pm 2.6 ; \mathrm{p}<0.0001)$ and $\mathrm{PM}$ total scores $(4.1 \pm 2.5$ versus $8.8 \pm 1.2 ; \mathrm{p}<0.0001)$. Cornell Scale for Depression in Dementia (CSDD) showed no signs of depression in the de- mentia group (which presented scores from 0 to 2 ) nor in the control group (scores from 0 to 1).

The comparison of dementia subjects as for their performance on PM (total scores) versus RAVLT-recall revealed they were worse on this last test $(p<0.0001$; Wilcoxon test for paired samples). In this group, there were no statistically significant correlations (Spearman rank correlation coefficient, $r s$ ) between PM and RM performance $(p=0.535)$ nor between PM and neuropsychological control tests (visual perception, $r s=-0.069$; digit span forward, $r s=-0.095$; digit span backwards, $r s=-0.023$; trail making $A, r s=-0.225$; trail making $B, r s=0.091$; and MMSE, $r s=-0.115)$. In the control group there was no correlation between age and PM (Spearman $r s=-0.0187, p=0.937$ ).

\section{DISCUSSION}

All subjects could understand what was expected of them in the tasks proposed. Even those who failed in ProM tests could at the end of the experiment remember the instructions which had been given to them. As regards our two ProM tasks (Animals and Clock tests), they were constructed with basis on McDaniel and Einstein ${ }^{5}$ guidelines for creating typically prospective and informative tasks: (1) not to be executed immediately after the intention, but delayed or postponed to some point in the future; (2) to be embedded in another ongoing activity; (3) to have constrained time window of opportunities for initiating the intended action; (4) to have limited time frame for accomplishing the action; (5) to be based on an consciously formed intention or plan; and (6) the formed intention should not be maintained in working memory, in the focus of consciousness, but temporarily forgotten by performing other activities, otherwise it would constitute a vigilance task, not a PM task.

The inferior performance of dementia patients on ProM and other neuropsychological tasks cannot be accounted for by higher age, since their ages were not more than five years higher than those of their matched controls. Besides this age difference being small, the effect of age on cognitive performance is usually secondary to the effect of educational level ${ }^{24-26}$, which was similar in our groups of patients and controls. Dementia patients failure on ProM tasks can neither be explained by deficit of attention, visual perception or executive function as there was no correlation between ProM and the control tests for these cognitive functions.

Contrary to our expectations based on Craik's ${ }^{27}$ memory model, our mild AD patients performed worse on retrospective than on prospective memory tasks. This finding is, however, not surprising, since these patients were included insofar as they fulfilled DSM-IV criteria, which requires that all patients, by the start, must have impair- 
Table. Demographic data and neuropsychological scores of patients with dementia (AD1 to AD20) and normal controls (CO1 to CO20).

\begin{tabular}{|c|c|c|c|c|c|c|c|c|}
\hline Subjects & $\begin{array}{c}\text { Age } \\
\text { (years) }\end{array}$ & $\begin{array}{c}\text { Education } \\
\text { (years) }\end{array}$ & $\begin{array}{l}\text { RAVLT } \\
\text { recall }\end{array}$ & PM total & $\begin{array}{c}\text { Visual } \\
\text { perception }\end{array}$ & DSB & TM-B & MMSE \\
\hline AD1 & 74 & 4 & 0 & 5 & 5 & 3 & 5 & 17 \\
\hline AD2 & 78 & 1 & 0 & 7 & 8 & 3 & 10 & 22 \\
\hline AD3 & 81 & 2 & 3 & 2 & 8 & 3 & 8 & 22 \\
\hline AD4 & 92 & 4 & 0 & 7 & 8 & 3 & 24 & 24 \\
\hline AD5 & 82 & 4 & 0 & 0 & 8 & 3 & 16 & 24 \\
\hline AD6 & 56 & 4 & 4 & 9 & 8 & 4 & 24 & 24 \\
\hline AD7 & 80 & 5 & 0 & 3 & 7 & 4 & 8 & 22 \\
\hline AD8 & 60 & 16 & 0 & 1 & 7 & 2 & 10 & 23 \\
\hline AD9 & 75 & 1 & 0 & 3 & 7 & 3 & 7 & 20 \\
\hline AD10 & 68 & 4 & 0 & 6 & 6 & 3 & 12 & 19 \\
\hline AD11 & 78 & 4 & 1 & 1 & 8 & 3 & 13 & 24 \\
\hline AD12 & 76 & 4 & 0 & 3 & 10 & 5 & 16 & 24 \\
\hline AD13 & 73 & 3 & 0 & 1 & 8 & 4 & 15 & 24 \\
\hline AD14 & 79 & 15 & 0 & 2 & 9 & 4 & 11 & 24 \\
\hline AD15 & 76 & 15 & 1 & 0 & 9 & 4 & 17 & 23 \\
\hline AD16 & 79 & 4 & 1 & 1 & 10 & 3 & 8 & 23 \\
\hline AD17 & 69 & 3 & 5 & 6 & 10 & 3 & 19 & 24 \\
\hline AD18 & 80 & 8 & 0 & 1 & 7 & 3 & 5 & 23 \\
\hline AD19 & 79 & 8 & 3 & 6 & 9 & 3 & 9 & 24 \\
\hline AD20 & 77 & 4 & 4 & 3 & 9 & 3 & 8 & 22 \\
\hline $\mathrm{CO} 1$ & 70 & 4 & 8 & 9 & 8 & 4 & 22 & 30 \\
\hline $\mathrm{CO} 2$ & 77 & 2 & 3 & 9 & 9 & 4 & 23 & 30 \\
\hline $\mathrm{CO} 3$ & 77 & 4 & 2 & 10 & 7 & 3 & 1 & 29 \\
\hline $\mathrm{CO} 4$ & 88 & 5 & 4 & 7 & 9 & 4 & 20 & 25 \\
\hline $\mathrm{CO} 5$ & 78 & 4 & 8 & 9 & 10 & 5 & 24 & 29 \\
\hline $\mathrm{CO} 6$ & 57 & 4 & 8 & 9 & 8 & 5 & 24 & 30 \\
\hline $\mathrm{CO} 7$ & 77 & 4 & 7 & 7 & 9 & 4 & 8 & 30 \\
\hline $\mathrm{CO} 8$ & 60 & 12 & 10 & 8 & 8 & 3 & 23 & 29 \\
\hline CO9 & 74 & 2 & 6 & 6 & 9 & 4 & 24 & 28 \\
\hline CO10 & 68 & 4 & 5 & 8 & 9 & 4 & 18 & 30 \\
\hline CO11 & 81 & 4 & 7 & 10 & 8 & 5 & 24 & 29 \\
\hline $\mathrm{CO} 12$ & 74 & 4 & 9 & 10 & 10 & 6 & 24 & 30 \\
\hline $\mathrm{CO} 13$ & 77 & 4 & 6 & 9 & 10 & 4 & 24 & 27 \\
\hline CO14 & 75 & 18 & 8 & 10 & 10 & 5 & 24 & 30 \\
\hline CO15 & 71 & 16 & 13 & 10 & 10 & 4 & 24 & 29 \\
\hline CO16 & 75 & 4 & 6 & 10 & 10 & 4 & 24 & 28 \\
\hline $\mathrm{CO} 17$ & 70 & 4 & 9 & 7 & 8 & 3 & 20 & 30 \\
\hline $\mathrm{CO} 18$ & 80 & 8 & 3 & 6 & 10 & 3 & 24 & 29 \\
\hline CO19 & 76 & 6 & 5 & 8 & 9 & 3 & 22 & 29 \\
\hline $\mathrm{CO} 2 \mathrm{O}$ & 78 & 4 & 6 & 9 & 9 & 3 & 22 & 28 \\
\hline
\end{tabular}

DSB, digit span backwards; TM-B, trail making B; RAVLT, Rey auditory-verbal learning test; PM, prospective memory; MMSE, mini-mental state examination.

ment of episodic hippocampal RetM, but not necessarily of ProM. There are indications that ProM and RetM depend on different cognitive processes and different brain regions $^{28}$. As we found in our study, ProM does not need to correlate to RetM. ProM performance is more reliant on intention formation, strategic planning, self-initiated retrieval, and interruption or inhibition of ongoing actions, which are cognitive processes highly dependent on the frontal lobes but not on the hippocampal system ${ }^{29}$. In fact, positron emission tomography (PET) studies of young adults performing ProM tasks have found several localized brain activations, particularly in the right dorsolateral and ventrolateral prefrontal cortices, anterior cingulate gyrus, left parahippocampal gyrus, and midline medial frontal lobe ${ }^{30,31}$. The authors related these localized activations to specific cognitive operations involved in ProM, such as holding an intention toward future behavior, checking target items within presented stimuli, and dividing atten- 
tion between the planned ProM action and the routine activity in which it was embedded.

Although ProM was less deteriorated than RetM in our mild AD patients, it was markedly impaired in these patients as compared to normal controls, what suggests ProM may be an early indicator of dementia, as proposed by Huppert and Beardsall". In old subjects with preclinical $A D$ or mild cognitive decline (with MMSE scores ranging from 18 to 30) both ProM and RetM are weakened, with the impairment of ProM affecting equally its prospective and retrospective components ${ }^{28}$. Furthermore, most ProM studies of normal aging have observed differences between older subjects (in their 70s) and younger subjects (in their 50s), with the older ones performing worse $\mathrm{e}^{32}$, although some studies have found no age-related differences in $\mathrm{ProM}^{33}$, even in the context of age-related decline in RetM performance ${ }^{7,9}$. As shown in Maylor's study, these discordant findings may be explained by the degree of environmental support (cues) and processing demands present in the different ProM tasks employed by the authors. Thus, in spite of these controversies, the bulk of evidence supports Craik's model in understanding the different effects of normal aging on ProM performance.

In conclusion, this study provides clear evidence that ProM and, in higher degree, RetM are primarily and independently impaired in mild AD. Some of its limitations should, however, be mentioned. First, all patients had full-blown dementia syndrome (though mild, with CDR 1), what makes it difficult to establish ProM as an early marker of AD. Second, the sample size is small and the scoring systems of ProM and RetM are different, what creates difficulties in running statistical analyses and in coming to safer conclusions. This study could be further improved by increasing sample size, including subjects in the preclinical phase of the disease, and using ProM tasks whose scoring systems tackle its prospective and retrospective components and facilitate comparisons with RetM tasks.

\section{REFERENCES}

1. American Psychiatric Association. Diagnostic and statistical manual of mental disorders ( $4^{\text {th }}$ ed.). Washington, DC: APA, 1994.

2. Tulving E. Multiple memory systems and consciousness. Hum Neurobiol 1987;6:67-80.

3. Baddeley A. Working memory. Oxford: Clarendon Press, 1986.

4. Dubois B."Prodromal Alzheimer's disease": a more useful concept than mild cognitive impairment? Curr Opin Neurol 2000;13:367-369.

5. McDaniel MA, Einstein GO. Prospective memory: an overview and synthesis of an emerging field. Los Angeles, CA: Sage Publications, 2007.

6. Graf P, Uttl B. Prospective memory: a new focus for research. Conscious Cogn 2001;10:437-450.
7. Einstein GO, McDaniel MA. Normal aging and prospective memory. J Exp Psychol Learn Mem Cogn 1990;16:717-726.

8. Craik FIM. Age differences in human memory. In Birren JE and Schaie KW (Eds.). Handbook of psychology of aging. New York: Van Nostrand Reinhold, 1987.

9. Maylor EA. Age and prospective memory. QJ Exp Psychol 1990;42:471-493.

10. Cockburn J, Smith PT. Anxiety and errors of prospective memory among elderly people. Br J Psychiatry 1994;85:273-282.

11. Huppert FA, Beardsall L. Prospective memory impairment as an early indicator of dementia. J Clin Exp Neuropsychol 1993;15:805-821.

12. Driscoll I, McDaniel MA, Guynn MJ. Apoliprotein E and prospective memory in normally aging adults. Neuropsychology 2005;19:28-34

13. Duchek JM, Balota DA, Cortese M. Prospective memory and apolipoprotein E in healthy aging and early stage Alzheimer's disease. Neuropsychology 2006: 20:633-644.

14. McKhann G, Drachman D, Foltein M, Katzman R, Price DL, Stadlan EM. Clinical diagnosis of Alzheimer's disease: report of the NINCDSADRDA Work Group under the auspices of Department of Health and Human Services Task Force on Alzheimer's disease. Neurology 1984;34:939-944.

15. Folstein MF, Folstein SE, McHugh PR. Mini-Mental State: a practical method for grading the cognitive state of patients for the clinician. J Psychiatr Res 1975;12:189-198.

16. Brucki SMD, Nitrini R, Caramelli P, Bertolucci PHF, Okamoto IH. Sugestões para o uso do mini-exame do estado mental no Brasil. Arq Neuropsiquiatr 2003;61:777-781.

17. Morris JC. The clinical dementia rating (CDR): current version and scoring rules. Neurology 1993;43:2412-2414.

18. Rey A. L'examen clinique en psychologie. Paris: Presse Universitaire de France, 1958.

19. Wilson BA, Cockburn J, Baddeley AD. The Rivermead behavioral memory test. Titchfield, UK: Thames Valley Test Co., 1985.

20. Jones-Gotman M, Zatorre RJ, Olivier A, et al. Learning and retention of words and designs following excision from medial or lateral temporallobe structures. Neuropsychologia 1997;35:963-973.

21. Wechsler D. Wechsler Memory Scale-Revised: manual. San Antonio, TX: The Psychological Corporation, 1987.

22. Spreen O, Strauss E. A compendium of neuropsychological tests: administration, norms, and commentary ( $2^{\text {nd }}$ ed.). New York: Oxford University Press, 1998

23. Carthery-Goulart MT, Areza-Fegyveres R, Schultz RR, et al. Versão brasileira da escala Cornell de depressão em demência (Cornell depression scale in dementia). Arq Neuropsiquiatr 2007;65:912-915.

24. Damasceno A, Delicio AM, Mazo DFC, et al. Validation of the Brazilian version of mini-test CASI-S. Arq Neuropsiquiatr 2005;63:416-421.

25. Bertolucci PHF, Brucki SMD, Campacci SR, Juliano Y. O mini-exame do estado mental em uma população geral. Arq Neuropsiquiatr 1994;52:1-7.

26. Porto CS, Fichman HC, Caramelli P, Bahia VS, Nitrini R. Brazilian version of the Mattis dementia rating scale: diagnosis of mild dementia in Alzheimer's disease. Arq Neuropsiquiatr 2003;61:339-345.

27. Craik FIM. A functional account of age differences in memory. In Klix $\mathrm{F}$ and Hangerdorf $\mathrm{H}$ (Eds). Human memory and cognitive capabilities: mechanisms and performances. Amsterdam: Elsevier, 1986.

28. Jones S, Livner A, Bäckman L. Patterns of prospective and retrospective memory impairment in preclinical Alzheimer's disease. Neuropsychology 2006;20:144-152

29. McDaniel MA, Glisky EL, Rubin SR, Guynn MJ, Routhieaux BC. Prospective memory: a neuropsychological study. Neuropsychology 1999;13:103-110.

30. Okuda J, Fujii T, Yamadori A, et al. Participation of the prefrontal cortices in prospective memory: evidence from a PET study in humans. Neurosci Lett 1998;253:127-130.

31. Burgess PW, Quayle A, Frith CD. Brain regions involved in prospective memory as determined by positron emission tomography. Neuropsychologia 2001;39:545-555.

32. Mäntylä T, Nilsson LG. Remembering to remember in adulthood: a population-based study on aging and prospective memory. Aging Neuropsychol Cogn 1997;4:81-92.

33. Cherry KE, LeCompte DC. Age and individual differences influence prospective memory. Psychol Aging 1999;14:60-76. 